\title{
Dönüşen Kimlik: Reis Bey
}

\author{
Celal ASLAN* \\ Mustafa KAYA**
}

\section{$\ddot{\mathbf{O z}}$}

Necip Fazıl Kısakürek (1904-1983), şiir, anı, tiyatro olmak üzere birçok edebi türde eser vermiş velut yazarlarımız arasındadır. İkisi yarım kalmış on yedi piyesi bulunmaktadır. Reis Bey (1964), yayımlanan sekizinci tiyatro oyunudur. Oyun, adalet-merhamet kavramları odağında kurgulanmıştır. Çalışmamızda "merhamet" kavramının, sözlüksel anlamının yanı sıra "merhamet"i olumlayan Arthur Schopenhauer (1788-1860) ile olumsuzlayan Friedrich Nietzsche’nin (1844-1900) kavramla ilgili felsefi düşünceleri doğrultusunda oyunun tematik yapısı çözümlenmeye çalışılmıştır. Ayrıca bilişsel-davranışçı yaklaşım kapsamında Albert Ellis (1913-2007) tarafından ortaya konulan ABC modeli kapsamında, oyunun merkezî kişisinin kimliğinde gerçekleşen dönüşüm analiz edilmiştir. Oyunun merkezî kişisi Reis Bey’e, kurgulanan olay örgüsü içerisinde adalet-merhamet kavramlarını temsil etme rolü verilmiştir. Dolayısıyla çalışmamız, merkezî kişinin söylemlerine odaklanmıştır. Reis Bey’in yaşadığı değişim ve dönüşümün, oyunun düşünsel yapısında adalet-merhamet kavramlarına yüklenmiş olan anlamsal evren dikkate alınarak çözümlenmesi amaçlanmıştır. Bu nedenle oyunda gözlemlenen değişim ve dönüşümün; süreçsel aşamaları ve oyun kişisinin kimliksel dönüşümünün evreleri kurgusal yapının düşünsel/duyuşsal dayanakları dikkate alınarak betimlenmeye ve analiz edilmeye çalışılmıştır.

Anahtar Kelimeler: Necip Fazıl Kısakürek, Reis Bey, tiyatro, felsefe, merhamet, adalet, kimlik.

*Dr. Öğr. Ü., Van Yüzüncü Y1l Üniversitesi, Eğitim Fakültesi, Türk Dili ve Edebiyat Eğitimi Bölümü, Van, Türkiye. Elmek: celalaslann@gmail.com https://orcid.org/0000-0001-6729-4531.

**Doç. Dr., Van Yüzüncü Yıl Üniversitesi, Eğitim Fakültesi, Türkçe Eğitimi Bölümü, Van, Türkiye.

Elmek: m.kaya@yyu.edu.tr

https://orcid.org/00000003-4755-4994.

Geliş Tarihi / Received Date: 21.12.2020

Kabul Tarihi / Accepted Date: 12.01.2021 


\title{
Tranforming Identity: Reis Bey
}

\begin{abstract}
Necip Fazıl K1sakürek (1904-1983) is one of our prolific writers who wrote works in many literary genres such as poetry, memoirs and theater. He has seventeen plays, two of which were unfinished. Reis Bey (1964) is the eighth theater play published. The stage play is fictionalized on the concepts of justice and mercy. In our study, in addition to the lexical meaning of the concept of "mercy", the thematic structure of the play was tried to be analyzed considering the philosophical thoughts of Arthur Schopenhauer (1788-1860), who affirmed the concept of "mercy" and Friedrich Nietzsche (1844-1900), who negated it. In addition, the transformation in the identity of the main character of the stage play was analyzed within the scope of the ABC model introduced by Albert Ellis (1913-2007) within the scope of the cognitive-behavioral approach. The main character of the play, Reis Bey, was given the role of representing the concepts of justice and mercy in the plot. Therefore, our study focused on the words of the main character. It is aimed to analyze the change and transformation experienced by Reis Bey by taking into account the semantic universe loaded on the concepts of justice and compassion in the intellectual structure of the play. Therefore, the change and transformation observed in the play. The process stages and the stages of the identity transformation of the main character of the play were tried to be described and analyzed by considering the intellectual / affective foundations of the fictional structure.
\end{abstract}

Keywords: Necip Fazıl Kısakürek, Reis Bey, theater, philosophy, mercy, justice, identity. 


\section{Extended Summary}

Reis Bey (1964), the eighth product of Necip Faz1l Kısakürek's (1904-1983) playwrights that started with Tohum, is written - upon the request of the author Muhsin Ertuğrul to write a non-ideological work. Although Muhsin Ertuğrul made an effort to stage the play, as a result of the reactions of some actors who were uncomfortable with Necip Fazll's Islamic identity, the works were left unfinished and Reis Bey could not be staged at the Istanbul City Theaters. The attempt of Kent Oyunlar1, which includes Müşfik Kenter, to stage the play also failed for the same reasons. Reis Bey is a work with autobiographical elements and references including gambling, his bohemian life, his incomplete philosophy education in London, the author's grandfather, Hilmi Efendi's Reis Bey, and they are frequently encountered in the other works of Necip Fazll. It can be said that elements such as projections on the character are reflected in the fictional structure of the work. The work, written and directed by Mesut Uçakan, was transferred to the cinema in 1988.

The purpose of this study, in which Necip Fazıl's play Reis Bey was discussed was to describe and analyze the processual stages and the underlying intellectual / affective foundations of the change and transformation in the world of thought / emotion related to the compassion understanding of the main character, Reis Bey, who is at the center of the plot.

The main character of the work, Reis Bey, is depicted as an asocial character who has no surroundings, lives alone in a hotel room and built an imaginary wall between himself and people. The only thing that Reis Bey communicates with is an object: his diary in which he conveys his decisions in court and his thoughts on justice. Reis Bey, who makes sense of life and people with the focus of justice, takes a selfish and highly mechanical approach. He believes that justice should be established based entirely on facts and is of the opinion that there is absolutely no room for mercy in providing justice.

The real murderer is found after the suspect has been executed, and then Reis Bey retires. He tries to lead the formation of a new understanding of justice in the society by putting himself in the place of that young person. He becomes the apostle 
of the feeling of compassion, which he sees as the biggest obstacle to the development of the sense of justice in societies until now. It adds a whole new dimension to the concept of compassion: "When you understand forgiveness, you will forgive every person other than yourself." (Kısakürek, 1964: 47). It is seen that Nietzsche moved away from the understanding of mercy and turned towards the philosophy of Schopenhauer, one of the important philosophers of the 19th century.

In his future life, Reis Bey attributes the meaning of pity and forgiveness to the word mercy. By saying "Have mercy on every creature that bears life and heart!" (Kisakürek, 1964: 51), he states that every living thing should be compassionate. He believes that all kinds of bleeding wounds and problems in society can be overcome with feelings of forgiveness and pity. In his words of advice to the countryman whose daughter ran away "You too must forgive! And you should let her know so that she can return...When she knows better, she sure will forgive you ... " (Kisakürek, 1964: 47), he believes that feelings of forgiveness and pity will establish love and justice in society. However, Reis Bey sees being able to cry and being emotional as a precondition for forgiveness and pity.

The semantic content of the above verses taken from the Quran is not mentioned in the work, but it is perceived that the understanding of mercy based on Islamic references is positioned in the deep structure of the work in the context of the intellectual identity of the author. At this point, Reis Bey's belief that mercy will establish justice in the society gains a sufic dimension. It is understood from his answer "They would do well" (K1sakürek, 1964: 49) to the words of the owner of the coffee shop "They feel sorry for you otherwise. If they were not merciless, they would put a rope around your neck and walk you around the neighborhood." (Kısakürek, 1964: 49) that he sees his own self guilty of everything. His answer "'I do forgive! As I have forgiven yours..." (K1sakürek, 1964: 65) to the sarcastic question of the former prison director "Do you forgive every insult?" (Kisakürek, 1964: 65) shows that he sees everyone and every soul above his own self like a malāmatī. In addition, with his propositions "I cannot see a single person who has no right on me in this world ... So at least you forgive!", "Children, have mercy on people! Do not blame anyone but yourself!" (Kisakürek, 1964: 46), "Have mercy on every creature that bears life and heart!", it can be said that the feeling of compassion is given a universal dimension. 


\section{Reis Bey Üzerine}

Necip Fazıl Kısakürek; 1935'te Tohum'la başlayan oyun yazarlığının sekizinci ürünü Reis Bey'i -Muhsin Ertuğrul'un kendisinden ideolojik olmayan bir eser yazması isteği üzerine- 1964'te kaleme alır. Muhsin Ertuğrul, oyunun sahnelenmesi için çaba gösterse de Necip Fazıl'ın İslâmî kimliğinden rahatsızlık duyan kimi oyuncuların tepkileri neticesinde çalışmalar yarım kalır ve Reis Bey İstanbul Şehir Tiyatroları'nda sahnelenemez. Müşfik Kenter'in yer aldığı Kent Oyuncuları topluluğunun oyunu sahneleme girişimi de yine aynı nedenlerle sonuçsuz kalır. Reis Bey, Necip Fazıl'ın öteki eserlerinde de sıkça rastlanan, otobiyografik ögelerin ve göndermelerin bulunduğu bir eserdir: Kumar, bohem hayat1, Londra'da tamamlanmamış felsefe eğitimi', yazarın "İstanbul Cinayet ve İstinaf Mahkemesi Reisi” olan büyükbabası Hilmi Efendi’nin Reis Bey karakterine izdüşümleri gibi unsurların eserin kurmaca yapısına yansıdığı söylenebilir (Şen, 2017: 16, 35). Senaristliği ve yönetmenliği Mesut Uçakan tarafından yapılan eser 1988 yılında sinemaya aktarılmıştır.

\section{Anahtar Kavram: Merhamet}

Kâinatın öznesi konumunda olan insan, varlık âleminde birçok duygu ve düşünceyle donatılmış tek canlıdır. Âdeta mikro bir dünya görümünde olan insan, iç dünyasında yaşadığı sevgi, acıma, merhamet, hüzün gibi pek çok duyguya sahip yegâne varlık konumundadır. İnsanın iç dünyasında yaşadığı kimi duyguları bireyin kendisiyle ve iç dünyası ile alakalı iken kimi duyguları da bireyin hem kendisi hem de toplumsal yapıyla ilgilidir. Bu duygulardan bazıları bireysel ilişkilerde önemli iken bazıları da hem bireysel hem de toplumsal yapının içerisindeki birlik ve bütünlüğün inşa edilmesi açısından büyük önem arz etmektedir. Toplumdaki bireylerin yekvücut olmasından tutun da yeryüzünde yaşayan farklı millet-

1 Annesinin elmaslarını çalıp annesini öldürmekle suçlanan oyun kişisi Mahkûm, Londra'da devam ettiği felsefe eğitimini kumar, eroin bağımlılığı ve bohem hayatı yüzünden yarım bırakmıştır. Nilüfer İlhan (2015: 101) oyun kişisi Mahkûm'un Paris'e felsefe tahsili için gittiğini belirtmektedir, oysa Paris'e felsefe tahsili için giden bizatihi yazarın kendisidir. Otobiyografik benzerliklerin, sehven de olsa, bu tür yanılsamalara zemin hazırladığı bu örnekten yola çıkarak söylenebilir. 
lerin bir bütün olmasında etkili olan en önemli duygulardan biri de merhamettir. Goldin ve Jazaieri (2017) merhametin bireysel, kişilerarası, toplumsal refahın ve iyi oluşun önemli bir bileşeni olduğunu ifade etmektedirler.

Dinlerin, mistik sistemlerin ve insanı merkeze alan ve ona değer veren felsefi yaklaşımların önemsediği ve ön plana aldığı evrensel değerlerin başında gelen merhamet (Dalgal1, 2019: 1) kelimesi Türk Dil Kurumu Türkçe Sözlüğünde (2011:1657) "bir kimsenin veya bir başka canlının karşılaştığı kötü durumdan dolayı duyulan üzüntü, acıma”, Biyoetik Terimler Sözlüğünde ise "Zor ya da daha kötü durumdaki bir kişi ya da gruba (insan kimi zaman insan dişındaki canlılara da) yönelik duygudur.” (Oğuz, vd. 2005: 172) olarak tanımlanmaktadır. Sözlükte “acımak, şefkat göstermek" anlamında mastar, "acıma duygusu, bu duygunun etkisiyle yapılan iyilik, lütuf" anlamında isim olarak kullanılan merhamet ve benzer anlamdaki rahmet kelimeleri başta Cenab-1 Hakk'ın bütün yaratılmışlara yönelik lütuf ve ihsanlarını ifade etmesinin yanı sıra insanlarda varolan, onları hemcinslerinin ve diğer varlıkların sıkıntıları karşısında duyarlı olmaya ve yardım etmeye sevk eden acıma duygusunu belirtmektedir. Ancak Türkçede merhamet Allah ile birlikte insanlara nispet edilirken rahmet ise özellikle Allah'a nispet edilerek kullanılmaktadır (Çağrıcı, 2004: 184). Dinî kaynaklarda, merhamet kavramının rahmet ve şefkat gibi kavramlarla anlamsal olarak yakın olduğu belirtilmektedir (Gör, 2013). Merhamet kavramının İngilizce karşılığı olarak “compassion, mercy, grace, agape, benignity, charity, ruth, pity, clemency, commiseration, loving-kindness, misercordia, charitableness " kullanıldığ1 görülmektedir (URL1). Cambrigde Oxford Sözlüğünde compassion sözcüğ̈ "Başkalarının çektiği ac1ya veya kötü şansa karşı güçlü bir sempati ve üzüntü hissi ve onlara yardım etme isteği” anlamında kullanılmaktadır (URL-2).

Karmaşık, çok yönlü psikolojik ve sosyal bir süreç olan merhamet; acıma, adalet, sempati, empati, yardımseverlik, diğerkâmlık, duyarlılık gibi birçok kavramla ilişkili olduğundan bu kavramların yerine kullanılmış olduğu veya bu kavramlarla benzer özellikler taşıdığıyla ilgili birçok fikir ileri sürülmüştür. Schopenhauer (2014: 88), merhamet sözcüğünün "insancıl” sözcüğüyle aynı anlamı ifade ettiğini belirtmiş ve kavramı insanlıkla eş değer görmüştür. Benzer şekilde Comte-Sponville (2004) merhameti insan olmakla bir görmesinin yanı sıra mer- 
hametin erdemlilik olduğunu belirtmiştir. Gilbert ve Procter'e göre (2006: 354355) merhamet; başkasının acısını ortadan kaldırma arzusudur. İnsanlar arasındaki duygu yoğunluğunun oluşmasını sağlayan merhametin zor durumdaki bireylere acımadan ziyade, onların bu durumdan kurtulmasını sağlamaya yönelik bir durum olduğu söylenebilir. Ersoy ve Köşger (2016: 1) merhameti, diğerlerinin sıkıntılarına empatik bakma eylemi olarak tanımlarken benzer şekilde Sayar (2015: 70) karşıdaki kişinin ayrı olduğunun bilinmesine rağmen duygudaşlık yapabilme hâli olarak ifade etmiştir. Hatta Paul Gilbert (2005: 9-11) merhametin hem bilişsel boyutta acının kaynağını anlamayı hem de davranışsal boyutta merhametli eylemlerde bulunmayı içerdiğini belirtir. Merhamet kavramının bu yönüyle de empati becerisiyle benzerlik gösterdiğini söylemek mümkündür. Karşıdaki kişinin çektiği acıya empatik bir bakış geliştiren birey bilişsel ve duyuşsal olarak o bireyi anlayabilir, bireyin sorununun çözümüne yönelik atacağı adımlar merhamet kavramı içerisinde kendine yer bulur. Hökelekli (2008: 78) de merhameti; başkasının sıkıntılarını fark edip onun derdine iştirak etme, ona acıma ve şefkat gösterme şeklinde tanımlamaktadır. Gör (2013: 18) ise merhameti başkasının zayıflık, dert ve problemlerine yakınlık gösterme ve bunların üstesinden gelmesi için ona destek verme olarak tanımlamıştır. Yardımseverlik, diğerkâmlık, sevgi, saygı, hoşgörü, güven, sabır, sorumluluk, alçakgönüllülük duyarlılık, adalet gibi birçok değer merhametin bir parçasını oluşturmaktadır (Dalgalı, 2019: 4). Sonuç olarak; sözü edilen her bir değerin, merhamet kavramına eklemlenmesiyle sözcüğün çok yönlü/anlamlı bir nitelik kazanması "merhamet"in kavramsal olarak bütüncül ve kesin bir tanımının yapılabilmesine olanak tanımaz. Bu bağlamda tekil olarak olumlu anlamlarla yüklü olan merhamet kavramının sübjektifliği ile nesnel ve rasyonel olması zorunlu adalet kavramı odağında kurgulanan Reis Bey oyununda karşıt olarak konumlandırılan değerlerin çatışması söz konusudur.

\section{İlk Aşama: Toplum İçin Adalet}

Eserin ana karakteri Reis Bey, hiç çevresi olmayan, bir otel odasında tek başına yaşayan, insanlarla kendi arasında âdeta hayali bir duvar örmüş asosyal bir karakter olarak betimlenir. Reis Bey'in iletişim kurduğu yegâne varlık bir nesnedir: mahkemede verdiği kararları ve adalet üzerine düşüncelerini aktardığı günlü- 
gü. Hayatı ve insanı adalet düşüncesi odağında anlamlandıran Reis Bey, bencilce ve oldukça mekanik bir yaklaşım içerisindedir. Adaletin tamamen olgulardan hareket edilerek tesis edilmesi gerektiğine inanmaktadır ve adaletin sağlanması hususunda kesinlikle merhamete yer olmadığ 1 kanaatindedir.

Bu aşamada; Reis Bey'in adalet ve merhamet kavramları karşısındaki tutumu ve yaklaşımı Nietzsche'nin merhamet anlayışıyla örtüşür. Nietzsche, merhamet duygusunun "yaşamın kendisine karamsar, sorunsal bir durum verdiğinden" (Nietzsche, 2003: 13) merhamet anlayışına karşı çıkmaktadır. Nietzsche, yaşam karşıtı, yaşamı zayıflatan duygulardan söz ederken merhamete özel bir yer ayırır (Ay, 2013: 201). Nietzsche'nin “Ahlakî eleştirisinin en önemli taraflarından birisi de acımaya karşı oluşudur” (Cameron, 2002: 62). Nussbaum'a (1994: 139’ten aktaran; Ay, 2013: 204) göre Nietzsche merhamet kavramına çeşitli yan anlamlar yüklemiştir. Temel olarak merhametin hem merhamet edende hem de merhamet edilende yetersizlik ve zayıfllğın onaylanması anlamına geldiği düşüncesindedir. Merhametin bir başka yan anlamının da acıyı artırdığını dile getirmiştir. Bunun yanı sıra merhametin intikam, zalimlikle ilişkili olduğunu belirtmiştir. Nietzsche, merhametin iç yüzünün, bencilliği de içerdiğini ileri sürerek merhametsiz olmanın savunusunu yapar. Ancak merhametsiz olma tümüyle acımayı dışlamaz. Zira Nietzsche'ye göre acıma duygusu, acıyanı merhametli olarak adlandırmay1 gerektirmez (Akt.: Ay, 2013: 212). Reis Bey'in adalet anlayışı ve merhamete karşı olan tavrı Nietzsche'nin bu çerçevedeki fikirleriyle örtüşmektedir. Otelde kalmakta olan köylü müşterinin kızı rahatsızdır, ertesi gün yapılacak ameliyatı beklemektedir. Hasta kız ister istemez hastalı̆̆ın kendine verdiği ıstıraptan dolayı inlemektedir. Reis Bey, bu iniltiden rahatsız olur ve otel lobisindeki görevliye bu rahatsızlığını iletir. Bu duruma şahit olan kızın babası, Reis Bey'den merhamet etmesini rica ettiğinde Reis Bey'in tepkisi: “- Sen de mi öğrendin bu lâfi? Ne kelimeler, ne duygular var; öğretemiyoruz da, sıra merhamete geldi mi, herkes ezbere biliyor. Ağızların iğrenç sakızı!” (Kısakürek, 1964: 16) şeklinde olur. Otel kâtibi, Reis Bey'e merhametin suç mu olduğunu sorduğunda Reis Bey'in cevab1 merhametin hem de idamlık bir suç olması gerektiği yönündedir. Otel lobisinde bulunan başka bir taşralı da "Bu adam hiç acımak nedir bilmez mi?" diye sorduğunda, otel kâtibi Reis Bey'in sürekli dillendirdiği “Benden, merhametin 
öldürdüklerine merhamet beklemeyiniz!” (K1sakürek, 1964: 17) cümlesiyle merhametsizliğin savunuculuğunu yaptığını dile getirir. Reis Bey, cezaevinde idama mahkûm olan gencin infazını gerçekleştirmek için gittiğinde cezaevi müdürü Reis Bey’i karşılar. Müdür, Reis Bey’e, cezaevinde intizamın tesis edildiğinden, işlerin ve düzenin gayet iyi olduğundan söz eder. Reis Bey, müdüre nasıl muvaffak olduklarını sorduğu zaman müdür, Reis Bey'in duymak istediği cevabı verir: " Zaafi, merhameti, yumuşaklı̆̆l kitaptan kazımak sayesinde...” (Kısakürek, 1964: 29). Reis Bey, bir müddet bekledikten sonra infazı gerçekleştirilecek, annesinin katili olmakla suçlanan genç gelir ve Reis Bey’e adalet ve merhamet anlayışının yanlışlığını dile getirir: "Siz ă̆layamazsınız! Ağlayabilseydiniz, anlayabilirdiniz! Siz merhametten, acıma duygusundan yalnız kötülük doğacă̆ına inanmışsınız. Yerinde haklısınız. Fakat ondan ne büyük iyilik doğacă̆ını unuttuğunuz için, en büyük hakkı kaybediyorsunuz. Rahmet, kaldırılmış sizin kalbinizden... Buz çölünde yol alıyorsunuz! Mühürlü kalbinizin; bir gün açılmasını dilerim.” (Kısakürek, 1964: 31). Ancak Reis Bey, idamlık gencin söylediklerinden etkilenmez görünür, infaz gerçekleşir ve Reis Bey, gece otel odasında günlüğünü tuttuğu defterine idamlık gencin söylediklerini yazar.

Reis Bey'in kendi bilişsel düzeyi ile idam edilen gencin söylediği gerçeklik arasında bir iç çatışma yaşandığı söylenebilir. Dökmen’e (2008: 41) göre kişi mevcut bilişsel dengesi ile çelişen yeni uyarıcılarla karşılaşırsa iç çatışma yaşar. Ancak Reis Bey'in kendi iç dünyasında yaşadığg soyut düzeydeki çatışmalar idam edilen gencin yanlışlıkla idam edildiği gerçeğinin ortaya çıkmasıyla somutlaşır. Klasik tiyatroda "Trajik kahramanın yaptığı bir hatayla bahtında bir dönüşüm olmasıyla ortaya çıkan durum" (Nutku, 2001: 47) olarak tanımlanan "hamartia", Reis Bey'in yapmış olduğu kritik hata olarak belirlenebilir. Trajik hatası neticesinde Reis Bey’in adalet ve merhamet anlayışında kökten bir değişim gerçekleşir. Reis Bey artık merhamet kavramının toplum için elzem olduğuna ve tüm kötülüklerin merhametle ortadan kalkacağına inanır. Aslında Reis Bey karakterinde önemli bir değişim sağlayan olay, gencin yanlışlıkla idam edilmesinden ziyade masumiyetini ispatlayamayan bir insanın çaresiz çırpınışlarına karşı Reis Bey’in kör ve sağır kalmış olmasıdır. Reis Bey’in yasalar üstü birtakım öznel değerlerle örülü hukuk anlayışının kurbanı olan masum gencin idamı, Reis Bey’in zihinsel 
ve duygusal değişimine zemin hazırlayarak adalet düşüncesinin de ters yüz olmasına yol açar. Reis Bey’in -ismiyle müsemma- merhamete söz hakkı tanımayan otoriter adalet anlayışı temelinden sarsılır ve yıkılır.

Bilişsel-davranışçı yaklaşım kapsamında Albert Ellis tarafından ortaya konulan $\mathrm{ABC}$ modeline göre $\mathrm{A}$, bizi etkileyen belli bir olay; $\mathrm{B}$, bu olaya ilişkin düşüncelerimiz; $C$ ise düşüncelerin etkisiyle ortaya çıkan duygularımız ve davranışlarımızdır (Dökmen, 2008: 104). Bu modeli Reis Bey karakterine uyarladığımızda annesini öldürmekle itham edilen gencin idam edilmesi (A) sebeptir, gerçek katilin ortaya çıkması sonrasında Reis Bey’in yaşadığı duygu ve düşünce değişimi $(\mathrm{C})$ ise sonuçtur. Bu süreçte B'lerin farkında olunmasa da değişime asıl sebep A değil, B' dir. Reis Bey’in başlangıçta kusursuz olarak gördüğü ve savunduğu katı adalet anlayışının, değişimine ve dönüşümüne zemin hazırlayan değerlerin inşasında da dolaylı/karşıt bir biçimde etkili olduğu söylenebilir. Oyunda hikâye edilen her iki davada da Reis Bey'in aslında adil bir hükme varmasını kolaylaştıracak yahut yasanın öngördüğü cezai işlemi hafifletecek deliller dururken Reis Bey'in katı bir yargıç rolünü sahnelemesi (B) düzleminde olaya ilişkin hakkaniyete uygun/sağlıklı bir akıl yürütmenin yokluğuna işaret eder. Oysa her iki davanın sanıkları hakkında, Reis Bey'in uygun gördüğü cezai kararların isabetsizliğine dair ön gönderim sayılabilecek veriler vardır. Fakat "dönüşen kimlik" olarak tasarlanan Reis Bey'in, iki davada da verdiği hükümlere dair şüphe etmesini gerektiren kanıtlara kayıtsızlığının, bizatihi eserin tezine dair yazar niyetini aksettirdiği ileri sürülebilir.

Bu bağlamda Reis Bey'e kurmaca bir metin değil de hukuki normlar açısından bakıldığında eserin temel önermesinin yanlışlığından söz etmek gerekir. Rabia Sağlam, eseri hukuki açıdan analiz ettiği çalışmasında adalet ve merhametin adil bir yargılamada -kavramların doğaları gereği- uyuşmazlık göstereceğini ileri sürer (2019: 297-304). Söz konusu çalışmanın önermeleri bağlamında Reis Bey'in düşünsel yapısının hukuksal açıdan kritik hatalarla malul olduğu söylenebilir. Oyunun merkezî kişisi Reis Bey’in adalet anlayışı, oyunda aktarılan iki davaya yapmış olduğu yargıçlığı üzerinden ele alındığında her ikisinde de hukuken yanlış kararlar verdiği görülür. Üstünde uyuşturucu yakalanan birini, suçlu olduğu kanıtlanmadan hapse mahkûm ederken cinayet davasında şüpheli olarak 
yargılanan kişinin, kesin kanıtlar olmaksızın, idamına hükmetmiştir. Reis Bey’in ilk davayla ilgili günlüğüne yazmış olduğu "mahrem fikirleri” adalet anlayışının mesleki normlardan uzaklığını belgeler niteliktedir: "Ben bu çocuğun esrar satıcısı olduğuna dair en küçük bir delil bulamadım. Aksine, onun her tavrından, hayret, dehşet ve mâsumiyet tüttüğüne şahidim. Fakat, ancak en merhametsiz ceza ölçülerinin kurtarabileceği çürük bir cemiyette, paltosunun astarında esrar bulunmuş bir insanı temize çıkaramam. Bu yüzden, bütün karşı delilleri reddediyor ve onu mahkûm ediyorum. (...) Mahkûm ettiğim, o değil, mücerred fiildir. Ferde verdiğim ceza isabetsiz olabilir; cemiyete aradı̆̆ım deva, isabetlidir. Varsın, bir kötünün bürünmesi ihtimali olan masumluk maskesini kullanılmaz hale getirmek için, bin mâsum feda edilsin..." (Kisakürek, 1964: 45-46). Reis Bey, cinayet davası sanığına verdiği idam hükmüne dair kanaatini mahrem fikir olarak tutmaz, hapishane müdürüne hitaben "Ceza felsefesinde bir görüş vardır: Bir masuma kıymaktansa, bin cürümlüyü cezasız bırakmak yeğdir. Ben de diyorum ki, cemiyette bir ferdi korumak için, bin kişiye bu gömleği giydirmekten kaçınmamalıdır. $O$ bir kişi, bütün bir cemiyettir.” (K1sakürek, 1964: 28-29) der. Mahkeme sürecinde hiç varlık göstermeyen Savcı, ilk kez Reis Bey’e "Bence yanlış!..” (Kısakürek, 1964: 29) yanıtıyla itiraz eder ancak Reis Bey’in bu itirazı duymazlıktan gelmesi otoriter kimliğinin bir başka dışavurum örneği olarak oyuna eklenmiş olur.

Her iki davada da Reis Bey, adalete aykırı davranmış olmakla birlikte eserde adaletsiz kararlarının biricik nedeni "merhametsiz" oluşuna bağlanmıştır. Oysa Reis Bey'den beklenen yasalara uygun hareket etmesidir; yasaların katı olmasının, yasaya/adalete aykırı karar vermenin gerekçesi olamayacağı açıktır. İkinci dava olan cinayet mahkemesinde de benzer tutarsızlıklar sergilenir. Mahkûm'un avukatı mahkemede "Hâkim itham etmez, ancak takdir eder." (Kısakürek, 1964: 19) itirazıyla Reis Bey’e mesleki prensipleri anımsatsa da olumsuz yanıt alır. Cinayet davasının mahkeme süreci, Reis Bey'in otoriter kimliği ve keyfi adalet anlayışının sahnelendiği kesitlerdir ve Reis Bey âdeta tek kişilik bir oyun sergilemektedir; ne avukat ne de savcının davanın gidişatına tesiri olmaz.

İdam edilen gencin avukatı Reis Bey'e anahtarı başkasının alabileceğini söylediğinde Reis Bey, bu savı dikkate bile almayı adalette ihtimallere değil olgulara yer verilmesi gerektiğini dile getirmesinin yanı sıra adalet anlayışında insanı bir 
meta gibi düşünüp merhamet duygusuna hiç yer vermediği tezi gencin yanlışlıkla idam edilmesinde birincil neden olarak yansıtılır. Oysa yanlış karar Reis Bey’in merhametsiz oluşundan değil yasayı yanlış uyguluyor olmasından kaynaklanır. Her ne sebeple olursa olsun gencin yanlışlıkla idam edilmesi Reis Bey'in duygu ve düşünce dünyasında yepyeni bir anlayış meydana getirir. Artık Reis Bey, merhamete ağızlardaki iğrenç bir sakız olarak bakmak yerine, insanın/toplumun biricik kurtuluş reçetesi gözüyle bakmaktadır. Bu aşamada Reis Bey’in özeleştirisinin dayanağı, eserin tezine paralel olarak "merhametsizlik" odağında işlenir.

\section{İkinci Aşama: Akreplerle Halleşmek}

Reis Bey, şüpheli gencin idam edilmesinin ardından gerçek katilin bulunması üzerine emekliye ayrilır. Âdeta o gencin yerine kendini koyarak toplumda yeni bir adalet anlayışının oluşmasına reislik etmeye çalışır. Şimdiye kadar toplumlarda adalet duygusunun gelişmemesinin en büyük engeli olarak gördüğü merhamet duygusunun havarisi olur. Merhamet kavramına yepyeni bir boyut kazandırır: "Affi anlayınca, kendinizden başka her insanı mazur göreceksiniz." (Kısakürek, 1964: 47) düşüncesiyle Nietzsche'nin merhamet anlayışından uzaklaşıp 19. yüzyılın önemli fillozoflarından biri olan Schopenhauer'ın merhametle ilgili felsefesine yöneldiği görülür. Schopenhauer'e göre insanı insan ve insanc1l yapan yegâne duygu merhamettir; bu duygu insanı gerçek ahlaka eriştirmesinin yanı sıra adalet ve insan sevgisine de ulaştırır. Bir davranış merhamet duygusuyla ortaya çıkmışsa o davranışa ahlaki bir değer atfedilebilir. Bunun dışındaki güdü ya da duyguların ahlaki olamadığını dile getirir (Akın, 2018: 128-130). Schopenhauer; ahlak, insan sevgisi ve adaletin ön koşulu olarak merhameti görür ve bütün erdemlerin merhametten doğduğuna inanır. İlhan'a (2015: 97-98) göre Arthur Schopenhauer, toplumda insana yaşama hürriyetini verecek ve dayanışmayı sağlayacak yegâne duygunun adaletten önce merhamet olduğunu ileri sürer. Merhamet, insanların iyi davranmasını sağlayan, toplumsal hayatta karşılaşılan birçok haksızlığın meydana gelmesini önleyen, menfaati göz ardı eden önemli bir duygudur. Çünkü insanın vicdanı en çok başkalarının acınacak durumda olmaması koşuluyla rahat eder (Çalışkan-Akçetin, 2016: 74).

Reis Bey bundan sonraki yaşamında merhamet kelimesine acımak ve affetmek anlamlarını yükler. "Can taşıyan, yüreği atan her yaratığa acıyın!” (K1- 
sakürek, 1964: 51) cümlesiyle her canlıya merhamet edilmesi gerektiğini dile getirir. Toplumda kanayan her türlü yaranın ve sorunun üstesinden affetmek ve acıma duygularıyla gelinebileceğine inanmaktadır. Reis Bey'in, kızı kaçan taşralı köylüye yaptığ1; "Sen de affetmelisin! Dönmesi için de affettiğini bildirmelisin... Aklı erince, o seni affetmeli..." (Kısakürek, 1964: 47) nasihatleri, bireyleraras1 uyumun da merhametle tesis edilebileceği inancına bağlanır. Ancak Reis Bey, affetme ve acımanın ön koşulu olarak ağlayabilmeyi ve duygulanmayı görmektedir. İlhan'a (2015: 98) göre ağlama eyleminin temelinde sevgi, merhamet ve hayal olduğu için katı kalpli ve hayal gücü olmayan insanlar kolay kolay ağlayamazlar. Bu sebeple ağlayabilen insanlar, yumuşak kalpli ve iyi yürekli olarak tasavvur edilir. Ağlamak öfkenin yumuşamasına sebep olduğu için ağlayan kişi, merhamet duyabilen, yumuşak kalpli olan kimsedir. Ağlamak ve sevmek eylemi ile merhamet duygusu arasında doğrudan bir ilişki vardır. Reis Bey, idam edilen gencin: "Etmeyin Reis Bey, siz ağlayamazsınız! Ağlayabilseydiniz, anlayabilirdiniz!” (Kısakürek, 1964: 31) cümlesini âdeta kendisine şiar edinir. Önce vicdan mahkemesinde kendisini yargılayıp kendi tabiriyle: "Muradım akreplerle halleşmek, onları okşamak..." (Kısakürek, 1964: 49) diyerek sürekli ağlamış ve yumuşamıştır. Ağlayarak benliğini yumuşatıp kendini anlamış, kendini anladıktan sonra da tüm insanları anlamaya başlamış ve insanları affetmek, onlara acımak ve merhamet etmenin ön koşulu olarak ağlamayı görmüștür: "Ağlayanlardan olmak dururken, üstelik ağlatanlardan olmak revâ mı?” (Kisakürek, 1964: 52).

Nietzsche, merhamet duymanın insanın kendisi olmasının önünde engel olduğu düşüncesindedir (Ay, 2013: 205). Zerdüşt'e şunları söyletir: "Bir tanık çağırırsınız iyi şeyler söylemek isteyince kendiniz için ve onu hakkınızda iyi şeyler söylemeye ayarttınız mı, siz de iyi şeyler düşünürsünüz kendiniz için” (Nietzsche, 1996b: 55). Zerdüşt’ün alıntıladığımız bu ikinci saptaması Nietzsche'nin, merhamet duymanın insanın kendisi olmasının önünde nasıl bir-engel teşkil ettiğini göstermesi bakımından önemlidir. Ancak Reis Bey karakterindeki dönüşüm Nietzsche'nin bu düşüncesiyle örtüşmez. Çünkü Reis Bey, merhamet duymaya başladığ1 andan itibaren kendisi olmuş ve özüne dönmüştür. Topçu'ya (2019: 105) göre merhamet acıyan ruhu yükseltir ve değerlendirir, insanı insanlaştırır. Schopenhauer'e göre bu duygu insanın başka insanlara sevgi duymasını sağlar. 
Pommier (2010) merhametin mutluluk, gelişmiş toplumsal ilişkiler gibi pozitif psikolojisinin sonuçlarıyla ilişkili olduğunu belirtmiştir. Neff'e (2003) göre merhamet duygusu bütün insanların kusurlu olabileceklerini ve hatalar yapabileceklerini göz önünde bulundurarak onları yargılamadan anlamayı, onlara karşı nazik ve sabırlı olmayı içerir. Reis Bey, zamanla Schopenhauer'ın merhamet anlayışından daha ileri boyutta bir anlayışa doğru yol almaktadır. Bu aşamada Reis Bey'in merhamet anlayış1, tasavvufi bir boyut kazanmaya başlar: "Can taşıyan, yüreği atan her yaratığa acıyın! Ağzından kemiğini çaldıran köpeğe, her parçası ayrı ayrı kıvranan solucana, tabanı yanan çakala... Hepsinin üstünde insana; buruş buruş beyni, alnı ve çenesiyle gözyaşı döken insana acıyın! Çocuklar, insana acıyın! Kendinizden başka kimsede suç aramayın!” (Kısakürek, 1964: 51).

\section{Nihai Aşama: Kurtuluş Reçetesi}

Merhamet kavramı İslam dininin yanı sıra Hristiyanlık, Musevilik, Hinduizm ve Budizm gibi pek çok dinî kaynak tarafindan bir değer olarak görülmektedir. Doğu gelenekleri, merhametin zihin ve beden üzerinde 1slah edici bir potansiyele sahip olduğu konusunda hemfikirdirler (Vivino vd. 2009). Bu hususta merhametin, insanlığın evrensel bir değeri olmasının yanı sıra gerek ilahi gerekse dünyevi kaynaklı hemen bütün düşünce sistemlerinde var olan ve değer olarak kabul edilen bir kavram olduğunu söylemek mümkündür.

Merhamet kelimesi Kur'an-1 Kerîm'de bir ayette geçerken (el-Beled 90/17) rahmet kelimesi 114 yerde geçmektedir. Bunun yanı sıra Allah'ın rahman ve rahim isimleriyle benzer kökten gelen farklı fiil ve isimler yer almaktadır, bu ayetlerin çoğunluğunda Allah'ın özellikle müminlere ve genel itibariyle insanlara ve diğer varlıklara yönelik lütuf ve ihsanlarından bahsedilmektedir. Örneğin Hz. Peygamber'in müminlere karşı çok şefkatli ve merhametli olduğu (et-Tevbe 9/128), Allah'ın eşler arasına sevgi ve merhamet koyduğu (el-Hadîd 57/27) bildirilmekte, yaşlı ana babalara merhametle muamele edilmesi gerektiği emredilmektedir (el-İsrâ 17/24). Kur'an-1 Kerîm'in yanı sıra hadislerde de rahmet ve merhamet kavramının gerek Allah'ın kullarına lütuf ve ihsanı gerekse de insanların birbirlerine ve diğer varlıklara yönelik acıma, ilgi ve yardımları bağlamında kullanılmıştır. (Çağrıcı, 2004: 184). Nitekim bir ayette: "Şanım hakkı için, 
size kendinizden öyle bir peygamber geldi ki sıkıntıya düşmeniz ona ağır gelir; size düşkündür, mü’minlere karşı çok şefkatlidir, merhametlidir.” (Tevbe, 128) ve bir başka ayette : "Ey Resulüm! Biz seni ancak âlemlere bir rahmet olarak gönderdik.” (Enbiya, 107) buyrulmaktadır (Kur'an-1 Kerim, 2001: 206-330).

Kur'an-1 Kerim'den alınan yukarıdaki ayetlerin anlamsal içeriği, eserde lafzen geçmez ancak yazarın düşünsel kimliği bağlamında eserin derin yapısına İslami referanslara yaslanan merhamet anlayışının konumlandırıldığı sezilir. Bu kertede Reis Bey'in, merhametin toplumda adaleti tesis edeceğine olan inanc1 tasavvufi bir boyut kazanır. Kahvehane sahibinin: "Sana actyorlar yoksa. Aclmasaydılar, boynuna ip takıp mahalle mahalle gezdirirlerdi." (K1sakürek, 1964: 49) sözlerine "İyi ederlerdi." (Kısakürek, 1964: 49) cevabıyla kendi benliğini her şeyin suçlusu olarak görür. Eski Reis Bey’in takipçi ve taklitçisi hapishane müdürünün alayc1 "Her hakareti bağışlar mısın?” (Kısakürek, 1964: 65) sözlerine verdiği “Bă̆ışlarım! Sizinkileri bağışladığım gibi...” (Kısakürek, 1964: 65) yanıtıyla herkesi ve her nefsi melamice kendi benliğinin üstünde görmektedir. Ayrıca "Üzerimde hakkı olmayan tek insan göremiyorum bu dünyada... Hiç olmazsa sen bağışla!”, “Çocuklar, insana acıyın! Kendinizden başka kimsede suç aramayın!” (Kisakürek, 1964: 46) önermelerinin derecesi artırılarak "Can taşıyan, yüreği atan her yaratığa acıyın!" yahut "Sökün sahte su borularını, ev ev merhamet şebekesini kurun! Tepelerinizdeki çatıları da yıkın, göklerle temasa geçin!.." (Kısakürek, 1964: 83) (Kısakürek, 1964: 50) yaklaşımıyla merhamet duygusuna evrensel bir boyut kazandirılır.

\section{Sonuç}

Bu çalışma kapsamında ele alınan Necip Fazıl'ın Reis Bey adlı oyununda, olay kurgusunun merkezinde yer alan ana karakter Reis Bey'in merhamet anlay1şıyla ilgili düşünce/duygu dünyasında gerçekleşen değişim ve dönüşümün süreçsel aşamaları ve ardında yatan düşünsel/duyuşsal dayanakları betimlenmeye ve analiz edilmeye çalışılmıştır.

Oyunun merkezî kişisi Reis Bey, toplumda adaletin tesis edilmesi konusunda merhametin bir engel teşkil ettiğini düşünmektedir ve bu kavramı "ağızlardaki iğrenç sakız” olarak tarif etmektedir. Bu aşamada Reis Bey’in merhamet 
anlayışının; Nietzsche'nin merhameti bir acizlik olarak gören fikirleriyle örtüştüğü söylenebilir. Reis Bey, annesinin katili olmakla suçlanan bir genci katı ve tavizsiz adalet anlayışının ürünü olan bir akıl yürütmeyle idama mahkûm eder ve idam kararının infazı gerçekleşir. Gencin hatalı bir kararla idam edildiği gerçeği ortaya çıkınca Reis Bey’in merhamet/adalet anlayışında ciddi bir dönüşüm meydana gelir. Bu aşamada Reis Bey, merhametin hem bireysel/toplumsal yaşam hem de adalet açısından bir zorunluluk olduğu inancına ulaşır ve adalet duygusunun fertten topluma uzanan yelpazede yeniden inşa edilme faaliyetine 'reislik' etme rolünü üstlenir. Reis Bey’in bu aşamada yaşadığı söz konusu değişiminin kodlarının; adalet ve insan sevgisinin ön koşulunu merhamet duygusu olarak tanımlayan Schopenhauer'1n felsefi düşünceleriyle örtüştüğü söylenebilir. Bununla birlikte Reis Bey oyununun düşünsel yapısında tasavvufi bir boyutun yansımaları da sezilir. Oyunun merkezî kişisi yeryüzünde işlenen tüm suçların faili olarak kendisini görür ve kendisinden başka herkesin affedilmesi gerektiğine inanır. Bunun yanı sıra can taşıyan, nefes alan her varlığa merhametle muamele edilmesi anlayışıyla merhamet kavramına hem tasavvufi hem de evrensel bir boyut kazandırır.

Reis Bey'in fiktif yapısını biçimlendiren çatışma ögeleri; yukarı-aşağı, ulvi-süfli karşıtlığında betimlenmiştir. Mahkûm’un, kötü alışkanlıkları nedeniyle sosyal ve bireysel statü açısından yukarıdan aşağıya düşmüş olması, Reis Bey’in merhametsizliğinin nedeni olarak betimlenir. Reis Bey, toplumun selameti için “aşağı düşenler”'in cezalandırılmasını adaletin tecellisi olarak görmektedir. Ancak dönüşen kimliği sonrasında adalet/merhamet anlayışında tersine bir tasavvurla karşılaşılır. Sonuç olarak eserin merkezî karakter odağında gösterdiği bütün bu paradoksal ögeler, adalet-merhamet karşıtlığını bir de yer ve gök metaforlarıyla somutlaştırmaya götürür.

Edebi eserde ideolojik/düşünsel yaklaşımların kurgusal yapıya olumsuz yansımaları çoğu zaman engellenemez. Reis Bey oyununda, Necip Fazıl'ın sanata yüklediği misyonun yansımaları yoğun bir biçimde hissedilir. Sanatın kutsal değerlere tercüman edilmesi yaklaşımının, oyunun çatışma ve karşıtlık üzerine kurulan yapısının kurucu ögesi olduğu söylenebilir. Bununla birlikte oyunun yüzeysel yapısında; söz konusu 'aşkınlık'ın, dolaylı bir söylemle ve ideolojik argümanlar kullanılmadan kurmaca evrenle harmanlandığı görülmektedir. 


\section{Kaynakça}

Akın, Ş. Handan (2018), "Merhamet Kavramı ve Schopenhauer'in Merhamet Yaklaşımının Değerlendirilerek Farklı Düşünürlerin Görüşleriyle Karşılaştırılması”, Türkiye Biyoetik Dergisi, 5 (3), s. 126-131.

Ay, Volkan (2013), "Nietzsche'de 'Merhamet' Kavramının Yeniden Değerlendirilmesi” Beytulhikme An International Journal of Philosophy, 3 (1), s. 199-215.

Barbara, Vivino, Thompson, Barbara, Clara, Hill, Nicholas Ladany (2009), "Compassion in Psychotherapy: the Perspective of Therapists Nominated as Compassionate", Psychotherapy Research, 19(2), s. 157-171.

Cameron, F. (2002). Nietzsche and the 'Problem' of Morality, New York: Peter Lang Publishing.

Comte-Sponville, André (2004), Büyük Erdemler Risalesi, çev. Işık Ergüden, İstanbul: Bilgi Üniversitesi Yayınları.

Çağrıc1, Mustafa (2004), “Merhamet”, Türkiye Diyanet Vakfi İslam Ansiklopedisi. Cilt: 29. Ankara: Türkiye Diyanet Vakfı Yayınları.

Çalışkan- Akçetin, Nurhayat (2016), "Merhamet ve Devlet: Schopenhauer”, Felsefe ve Sosyal Bilimler Dergisi, 21, s. 71-86.

Dalgalı, Büşra, (2019). Merhamet Odaklı Terapi Yaklaşımı ve Uygulamaları Üzerine Bir Değerlendirme. Bursa: Bursa Uludağ Üniversitesi, Sosyal Bilimler Enstitüsü.

Dökmen, Üstün (2008), İletişim Çatışmaları ve Empati, Ankara: Remzi Kitapevi.

Ersoy, Elif Gökçe; Köşger, Ferdi (2016), “Empati: Tanımı ve Önemi”, Osmangazi Journal of Medicine, 38, s. 1-9.

Gilbert, Paul (2005), Compassion: Conceptualisations, Research and Use In Psychotherapy, Canada: Routledge.

Gilbert, Paul; Procter, Sue (2006), “Compassionate Mind Training for People With High Shame and Self-Criticism: Overview and Pilot Study Of a Group Therapy Approach", Clinical Psychology and Psychotherapy Clinical Psychology Psychother, 13, s. 353-379.

Goldin, Philippe; Jazaieri, Hooria (2017), The Compassion Cultivation Training (Cct) Program, ed. Emma Seppälä, Emiliana Simon-Thomas, Stephanie L. Brown, Monica Worline, Daryl Cameron, James Doty, Oxford: Handbooks.

Gör, Fatih, (2013). “İlköğretim Din Kültürü ve Ahlak Bilgisi Öğretim Programında Merhamet Değeri”, Erzurum: Atatürk Üniversitesi, Sosyal Bilimler Enstitüsü.

Hökelekli, Hayati (2008), "Merhamet”, Dem Dergisi, 1(4), s. 78-84.

URL-1.Atalay, Hakan (10.12.2020), “(https://hakanatalay.wordpress.com/2015/02/24/merhamet)" 
URL-2. (https://dictionary.cambridge.org/tr/s\%C3\%B6zl\% $\mathrm{C} 3 \% \mathrm{BCk} /$ ingilizce/compassion? $\mathrm{q}=$ COMPASS\%C4\%B0ON Erişim Tarihi: 08.12.2020).

İlhan, Nilüfer (2015), "Buz Çölünden Gözyaşı Çetesine Yahut Adaletten Merhamete Bir Geçişin Serencamı: Reis Bey”, Bozok Üniversitesi Illahiyat Fakültesi Dergisi, 7 (7), s. 97-108.

Kısakürek, N. Fazıl (1964), Reis Bey, İstanbul: Ötüken Yayınları.

Kur'an-ı Kerim (2001), İstanbul: Hayrat Neşriyat.

Neff, Kristin (2003), “The Development of Validation of a Scale to Measure Self Compassion”, Self and Identity, 2(3), s. 223-250.

Nietzsche, Friedrich (2003), Deccal, çev. Oruç Aruoba, İstanbul: İthaki Yayınları.

Nutku, Özdemir (2001), Dram Sanatı, İstanbul: Kabalc1 Yayınevi.

Oğuz, Yasemin; Tepe, Harun; Büken, Nüket; Kucur, Deniz (2005), Biyoetik Terimleri Sözlüğü, Ankara: Türkiye Felsefe Kurumu Yayınları.

Pommier, Elizabeth Ann, (2010), The Compassion Scale. Texsas: The University of Texas at Austin, Presented to Faculty of the Graduate School.

Sağlam, Rabia (2019), "Yargıç Merhameti, Reis Bey’in Merhametsizliği”, "Hukuka Felsefi ve Sosyolojik Bakışlar-VIII” Sempozyumu İstanbul Barosu-HFSA Bildiriler 15-18 Mayıs 2017, İstanbul. İstanbul: İstanbul Barosu Yayınları.

Sayar, Kemal (2015), Merhamet, İstanbul: Timaş Yayınları.

Schopenhauer, Arthur (2014), Merhamet, çev. Zekai Kocatürk, İstanbul: Dergâh Yayınları.

Şen, Can, (2017), Necip Fazıl Kısakürek'in Tiyatroları Üzerine Bir İnceleme. Bartın: Bartın Üniversitesi, Sosyal Bilimler Enstitüsü.

Topçu, N. (2019), Ahlâk, İstanbul: Dergâh Yayınları.

Türk Dil Kurumu Türkçe Sözlük, (2011), Ankara: Türk Dil Kurumu Yayınları. 